\title{
Revealing the elemental distribution within latent fingermarks using synchrotron sourced $x$-ray fluorescence microscopy
}

Rhiannon E. Boseley, ab Buddhika N. Dorakumbura, ${ }^{\text {ab }}$ Daryl L. Howard, ${ }^{c}$ Martin de Jonge,c Mark J. Tobin,c Jitraporn Vongsvivut,c Tracey T. M. Ho,c Wilhelm van Bronswijk,a Mark J. Hackett*ab and Simon W. Lewis*ab

a School of Molecular and Life Sciences, Curtin University, GPO Box U1987, Perth, Australia b Curtin Institute of Functional Molecules and Interfaces, GPO Box U1987, Perth, Australia c ANSTO, Australian Synchrotron, 800 Blackburn Road, Clayton, Victoria, Australia

*Corresponding authors: s.lewis@curtin.edu.au, markj.hackett@curtin.edu.au

\section{SUPPORTING INFORMATION}

- Supporting Information Figures 1 - 4: Images showing co-localisation of metal ions with eccrine material

- Supporting Information Figures 5-11: Additional elemental maps for latent fingermarks

- Supporting Information Figures 12 - 19: Large scale elemental maps for latent fingermark shown in Figure 1

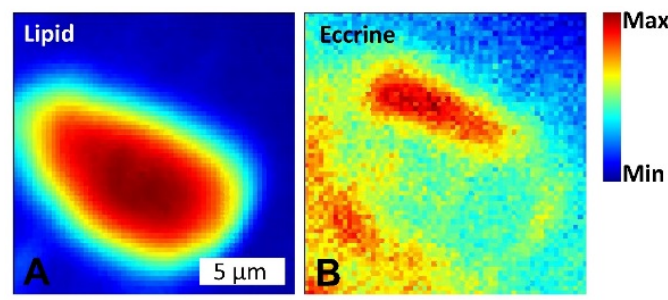

Supporting Information Figure 1 We have previously shown that the organic composition of natural fingermakrs reflects an emulsion of sebaceous (lipohillic, A) and eccrine (hydrophilic, B) components. The natural fingermarks deposited from donours analysd in this study were confirmed to display these same chacteristics. The FTIR images were collected at the infrared microscopy beamline at the Australian Synchrotron, using synchrotron ATR-FTIR microscopy, as previously reported. ${ }^{7}$
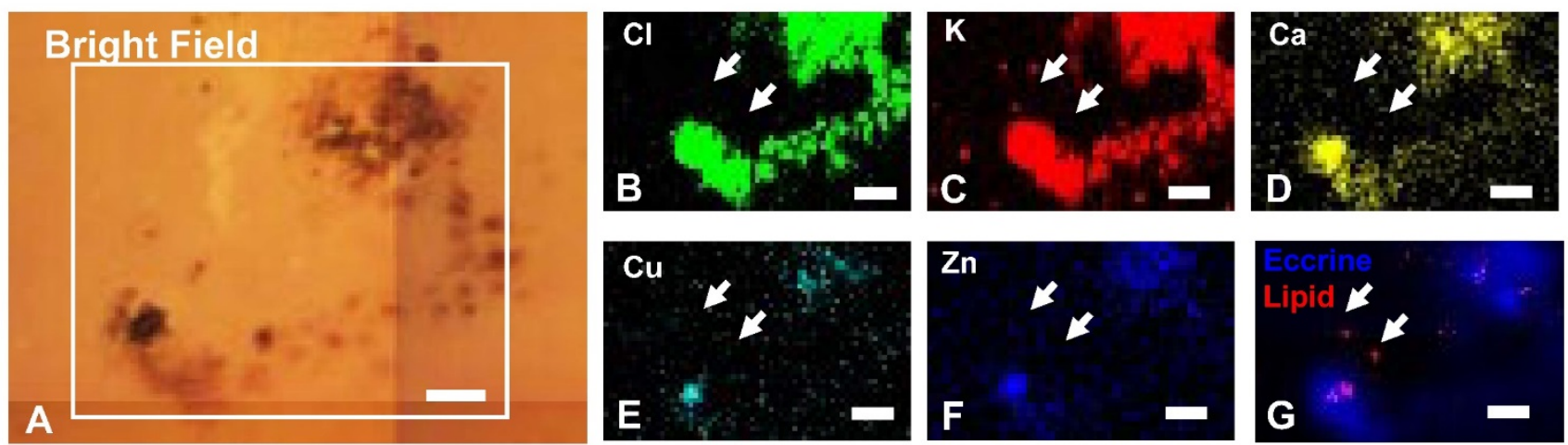

Supporting Information Figure 2 A zoomed in region of a natural fingermark containing both eccrin and sebaceous material. Bright field image (A), elemental maps of $\mathrm{Cl}(\mathrm{B}), \mathrm{K}(\mathrm{C}), \mathrm{Ca}(\mathrm{D}), \mathrm{Cu}(\mathrm{E}), \mathrm{Zn}(\mathrm{F})$, and an overlay of eccrine material and sebaceous material revealed by FTIR imaging (G). The FTIR images clearly show two distinct sebaceous lipid rich droplets, separate from the main fingermark deposit (white arrows). XFM did not detect $\mathrm{Cl}$, $\mathrm{K}$, Ca, $\mathrm{Cu}$, $\mathrm{Zn}$ enrichment in the sebaceous droplets, but these elements were enriched in the adjacent eccrine material. Scale $=10 \mu \mathrm{m}$. 


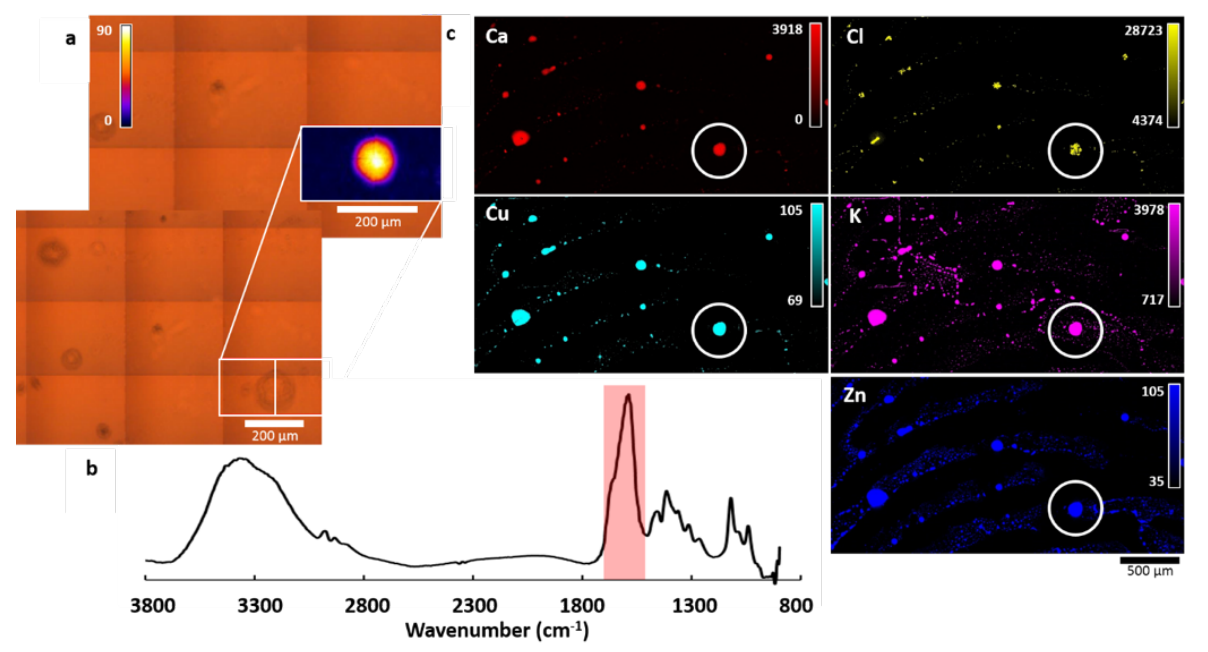

Supporting Information Figure 3 Natural fingermark from Donor 2, deposited on a silicon nitride slide. Bright field optical image of the area investigated with FTIR-FPA imaging with false colour image generated by integrating over the $0-\mathrm{H}$ bending band for the eccrine material (1520-1720 $\mathrm{cm}-1$ ) (a) FTIR spectra of eccrine material obtained using the conventional FTIR spectroscopy (b) and the corresponding elemental distribution maps imaged using XFM (c). XFM Concentration Scale Bar (ng cm-2)

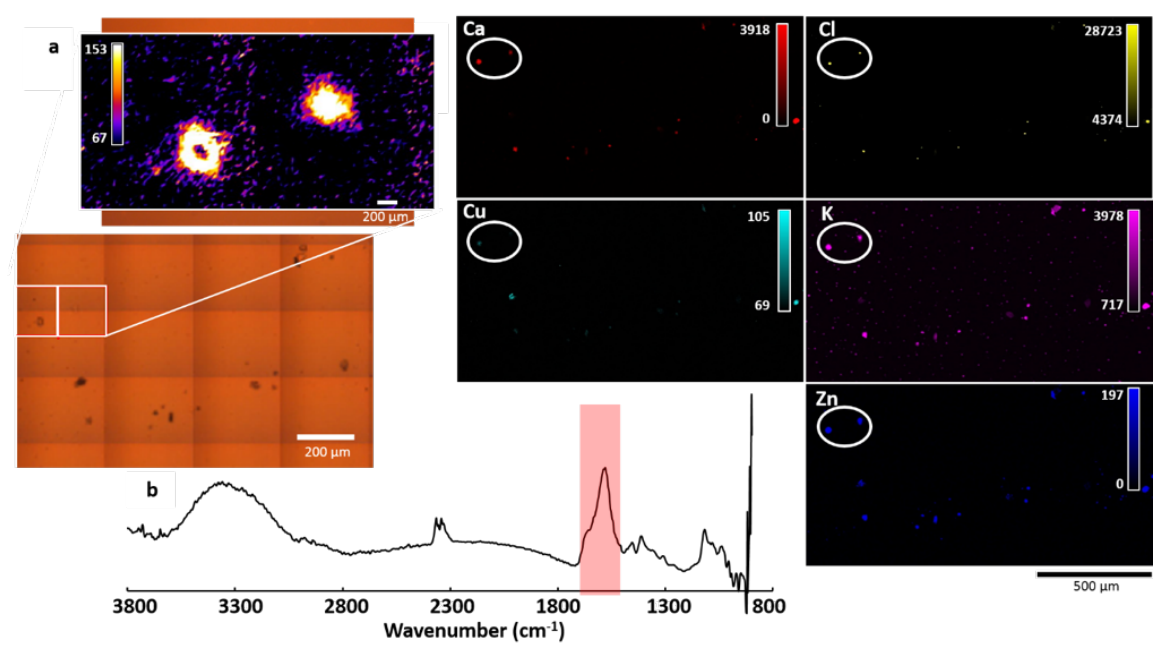

Supporting Information Figure 4 Natural fingermark from Donor 8, deposited on a silicon nitride slide. Bright field optical image of the area investigated with FTIR-FPA imaging with false colour image generated by integrating over the 0-H bending band for the eccrine material (1520-1720 cm-1) (a) FTIR spectra of eccrine material obtained using the conventional FTIR spectroscopy (b) and the corresponding elemental distribution maps imaged using XFM (c). XFM Concentration Scale Bar $\left(\mathrm{ng} \mathrm{cm}^{-2}\right)$ 


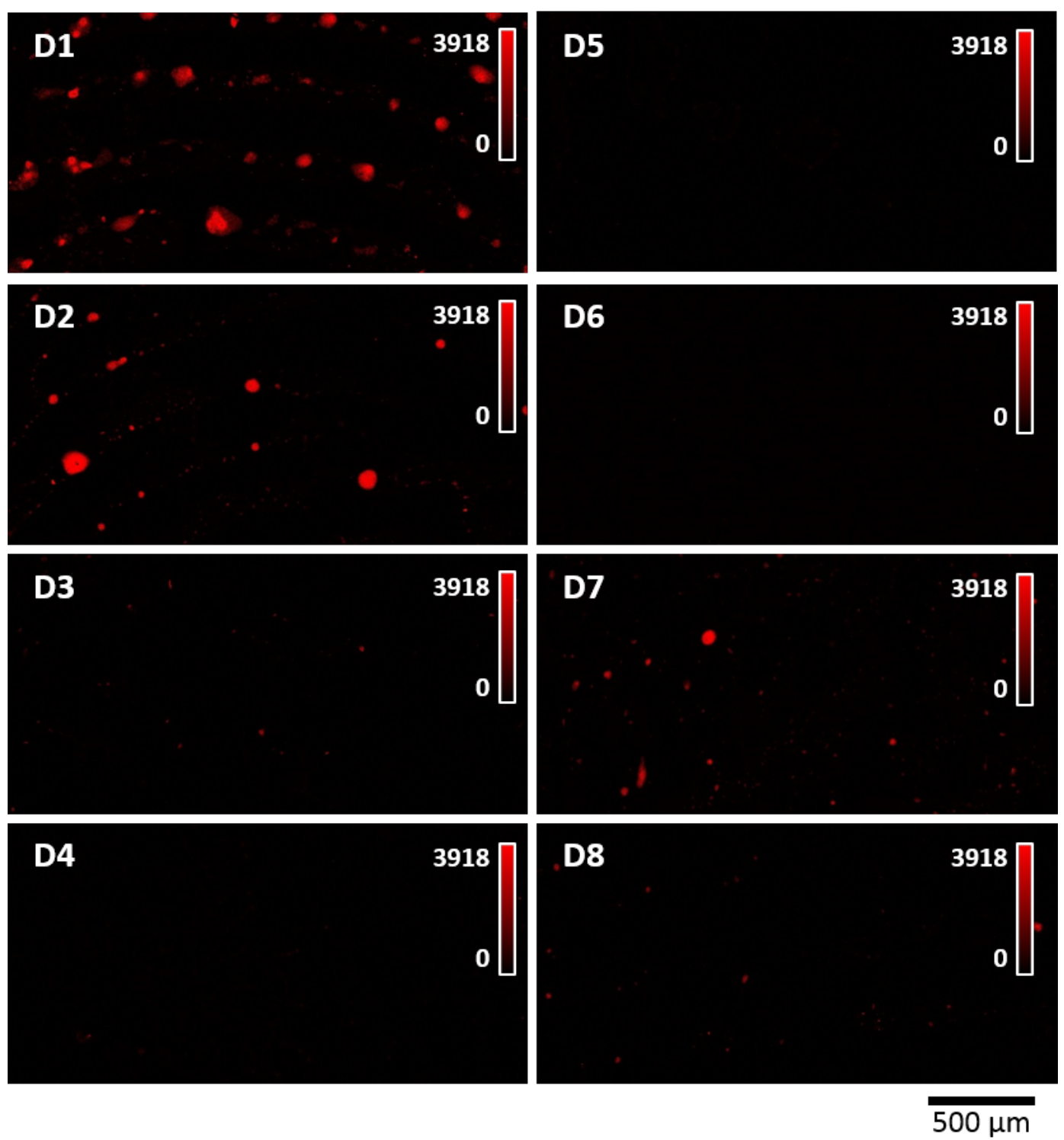

Supporting Information Figure 5 Typical results for calcium distribution within natural fingermarks collected from 8 donors on silicon nitride slides. Concentration Scale Bar (ng cm-2) 


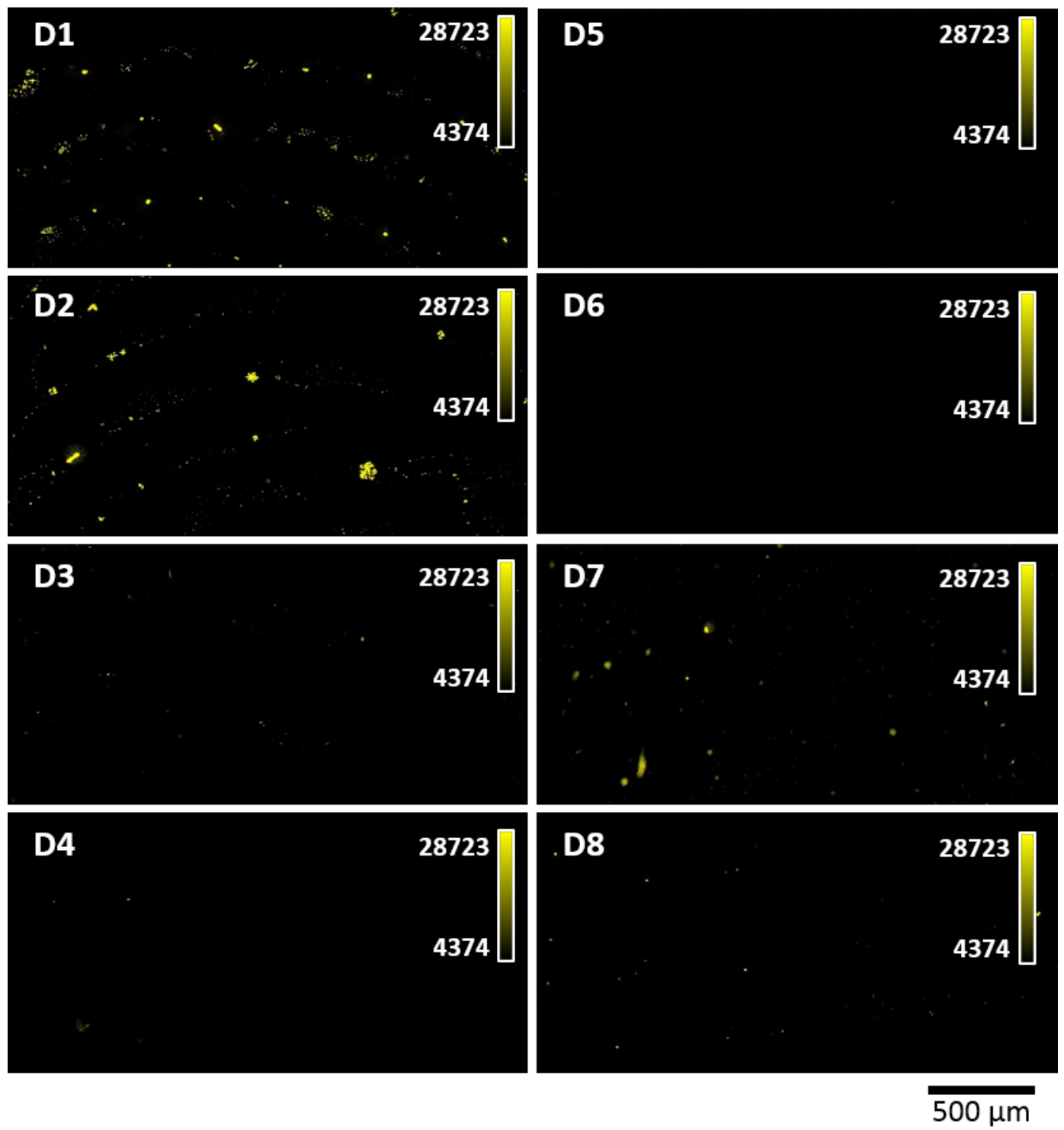

Supporting Information Figure 6 Typical results for chlorine distribution within natural fingermarks collected from 8 donors on silicon nitride slides. Concentration Scale Bar $\left(\mathrm{ng} \mathrm{cm}^{-2}\right)$ 


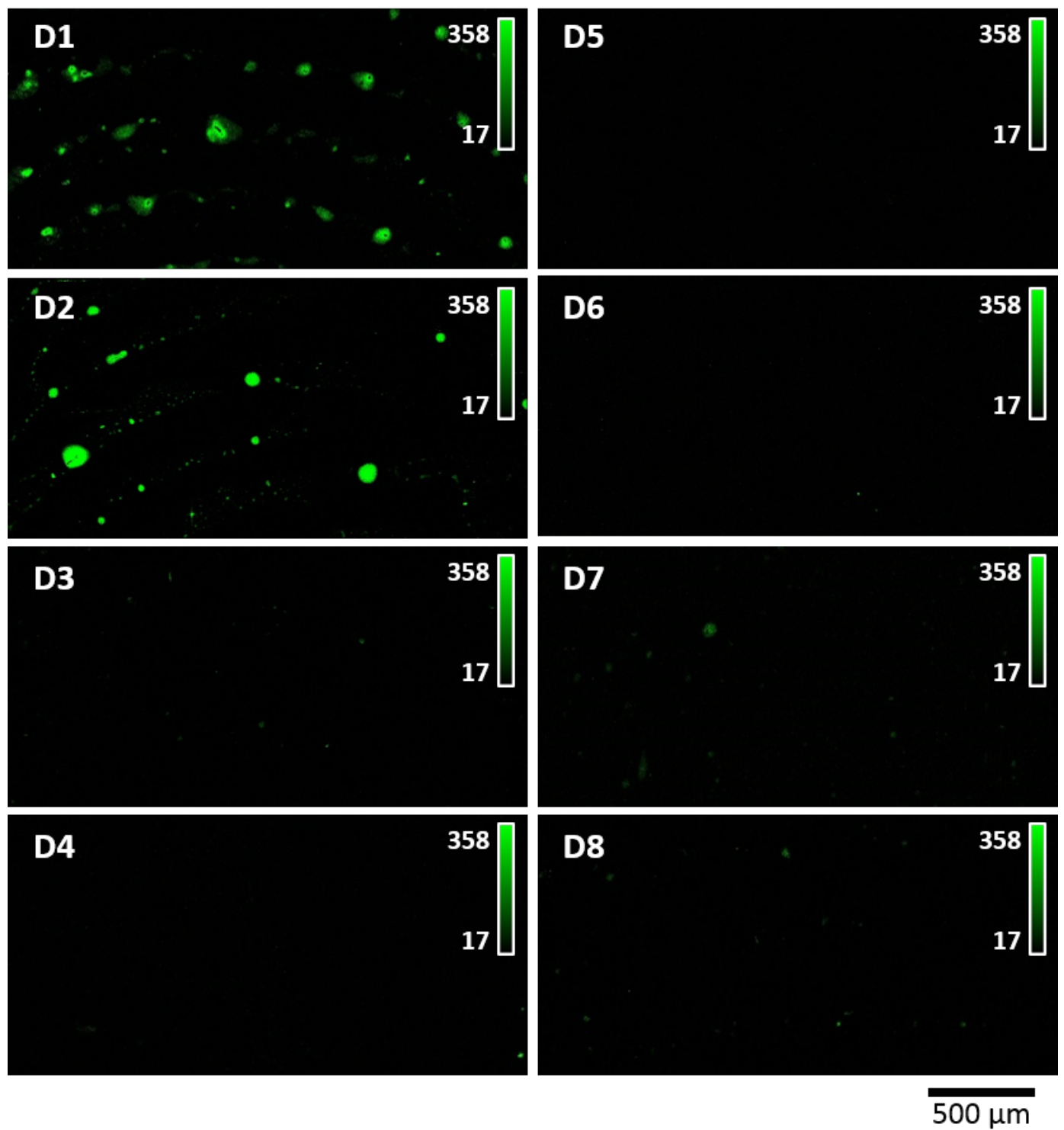

Supporting Information Figure 7 Typical results for copper distribution within natural fingermarks collected from 8 donors on silicon nitride slides. Concentration Scale Bar ( $\left.\mathrm{ng} \mathrm{cm}^{-2}\right)$ 


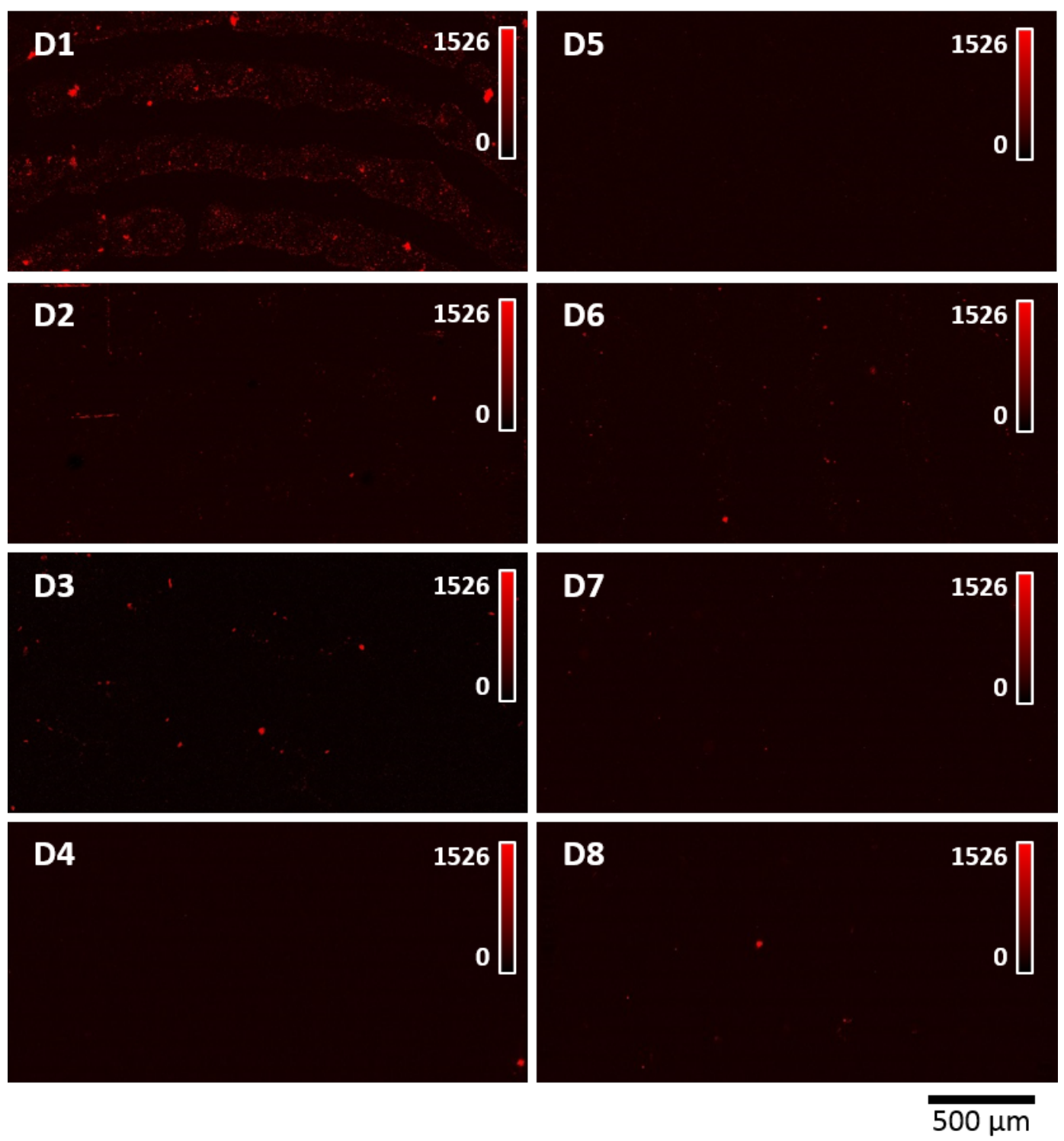

Supporting Information Figure 8 Typical results for iron distribution within natural fingermarks collected from 8 donors on silicon nitride slides. Concentration Scale Bar $\left(\mathrm{ng} \mathrm{cm}^{-2}\right)$ 

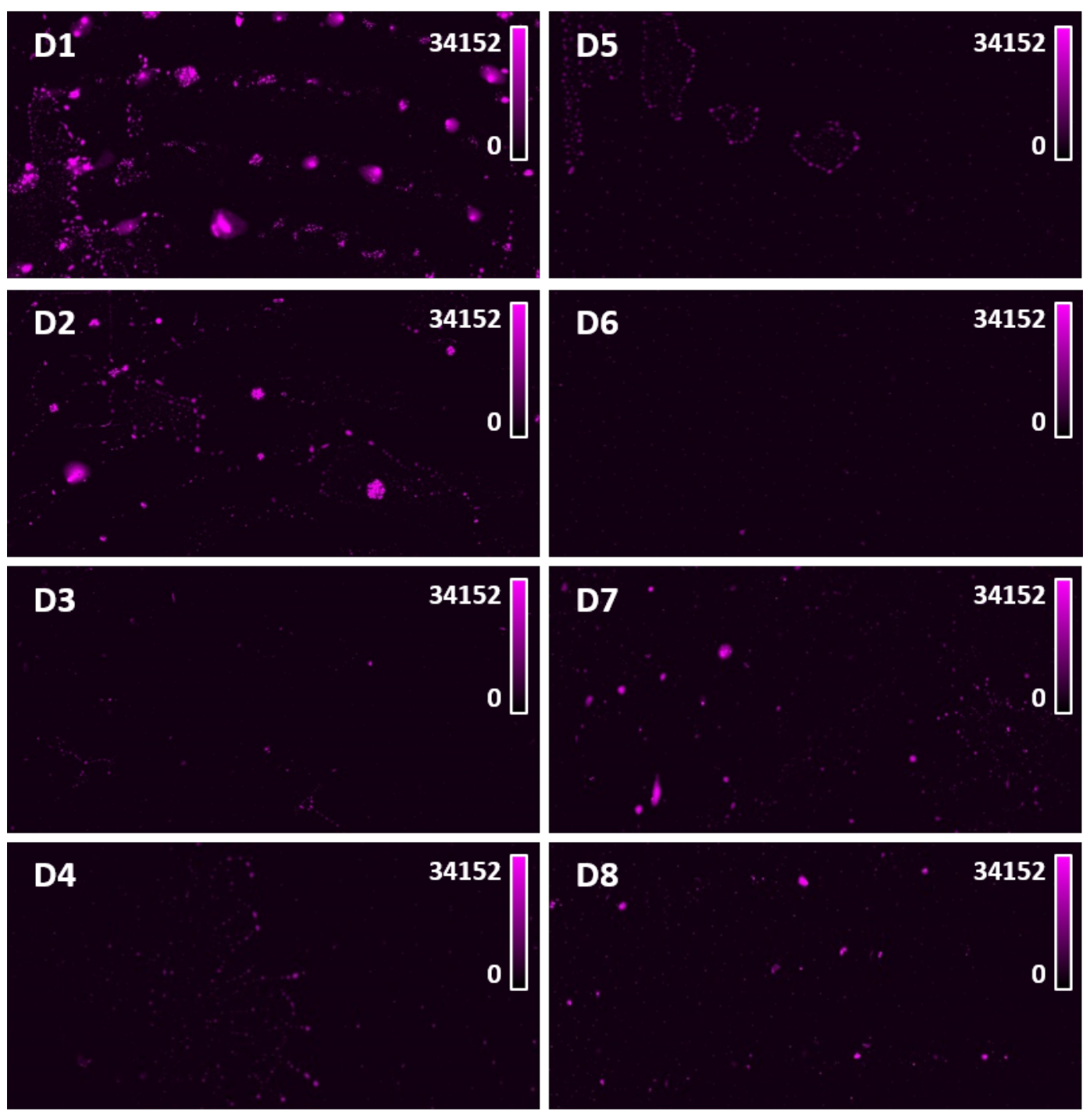

$\overline{500 \mu \mathrm{m}}$

Supporting Information Figure 9 Typical results for potassium distribution within natural fingermarks collected from 8 donors on silicon nitride slides. Concentration Scale Bar ( $\left.\mathrm{ng} \mathrm{cm}^{-2}\right)$ 


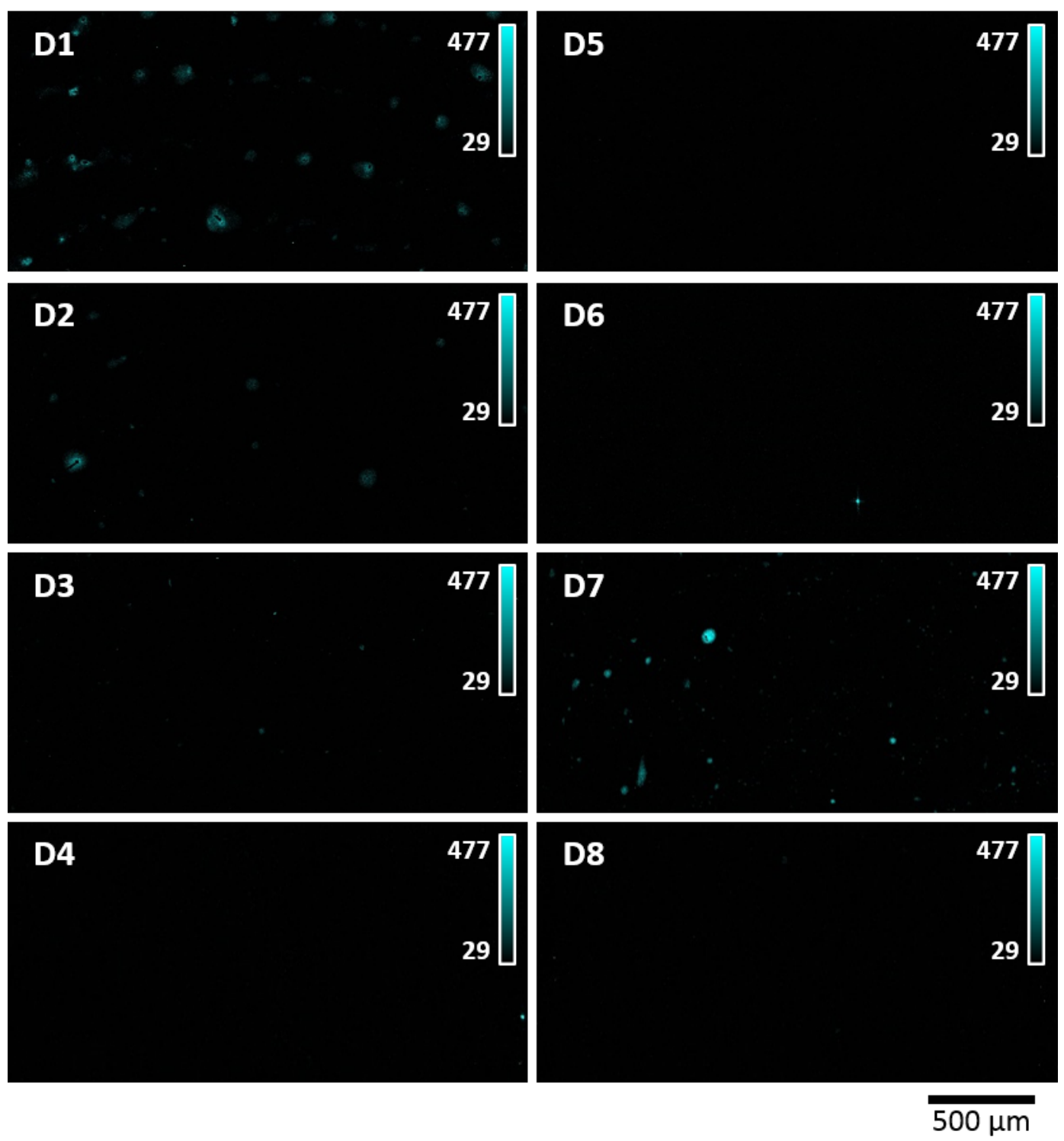

Supporting Information Figure 10 Typical results for nickel distribution within natural fingermarks collected from 8 donors on silicon nitride slides. Concentration Scale Bar $\left(\mathrm{ng} \mathrm{cm}^{-2}\right)$ 


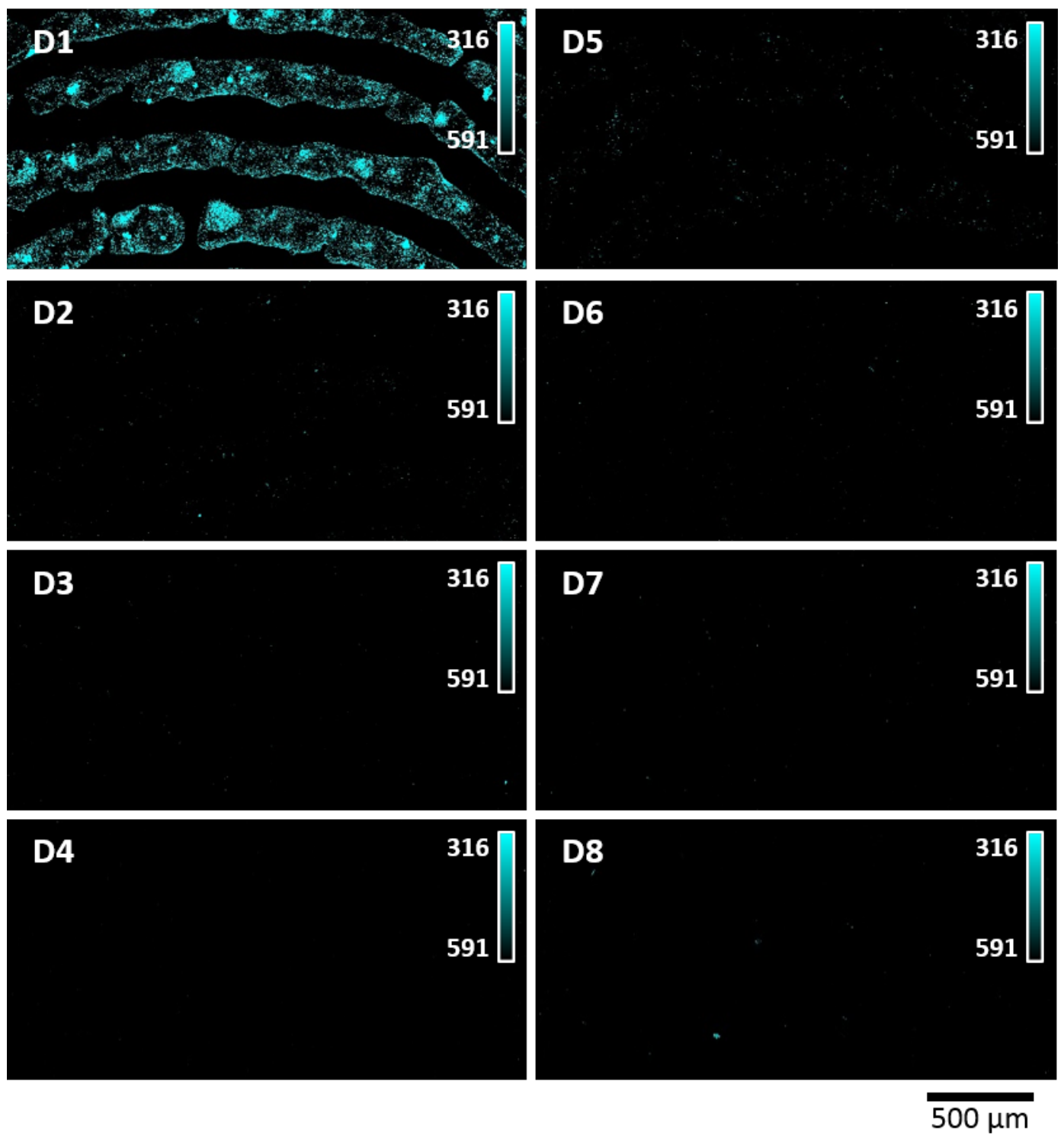

Supporting Information Figure 11 Typical results for titanium distribution within natural fingermarks collected from 8 donors on silicon nitride slides. Concentration Scale Bar ( $\left.\mathrm{ng} \mathrm{cm}^{-2}\right)$ 


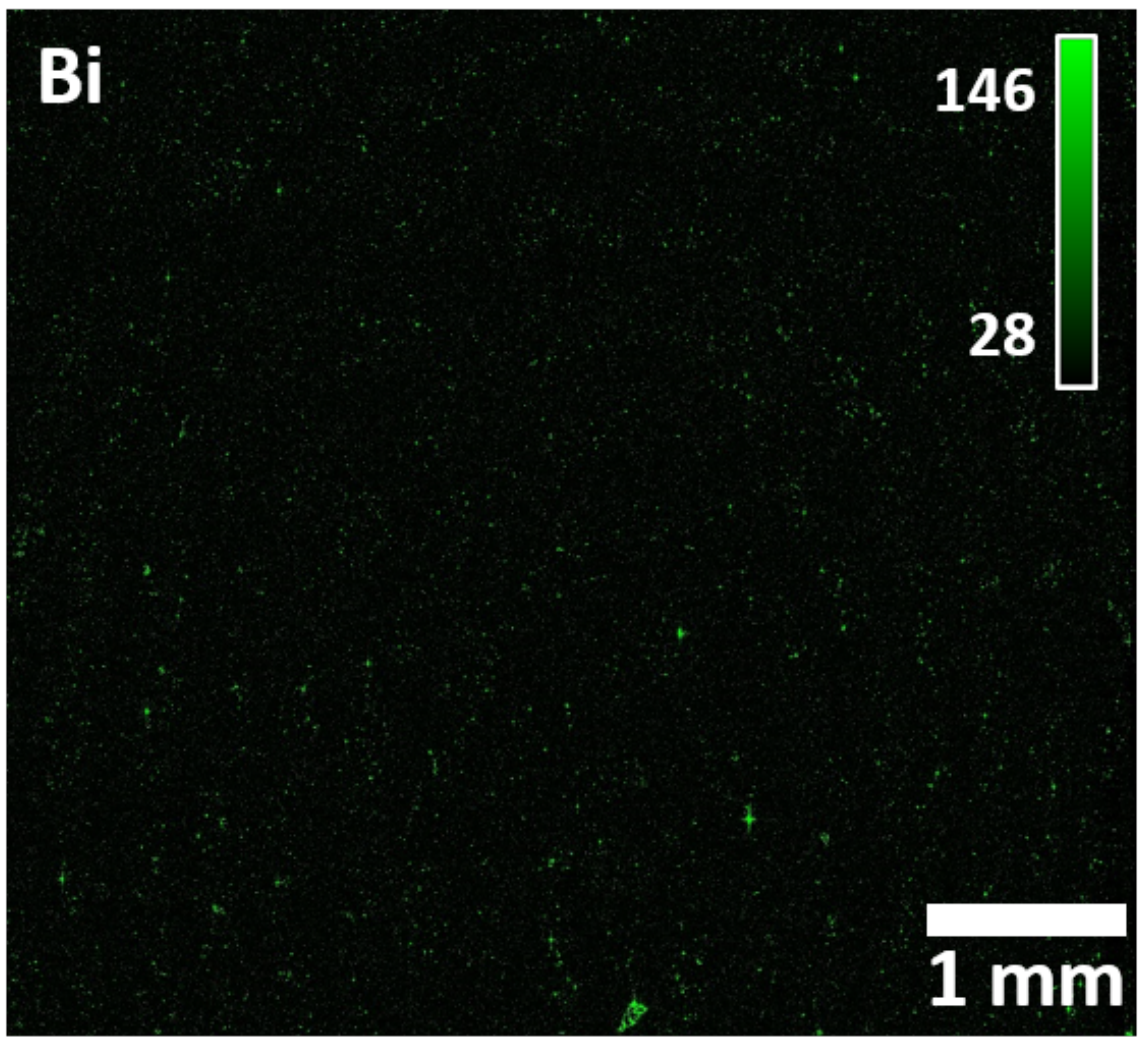

Supporting Figure 12 Large scale Bi map as shown in Figure 1

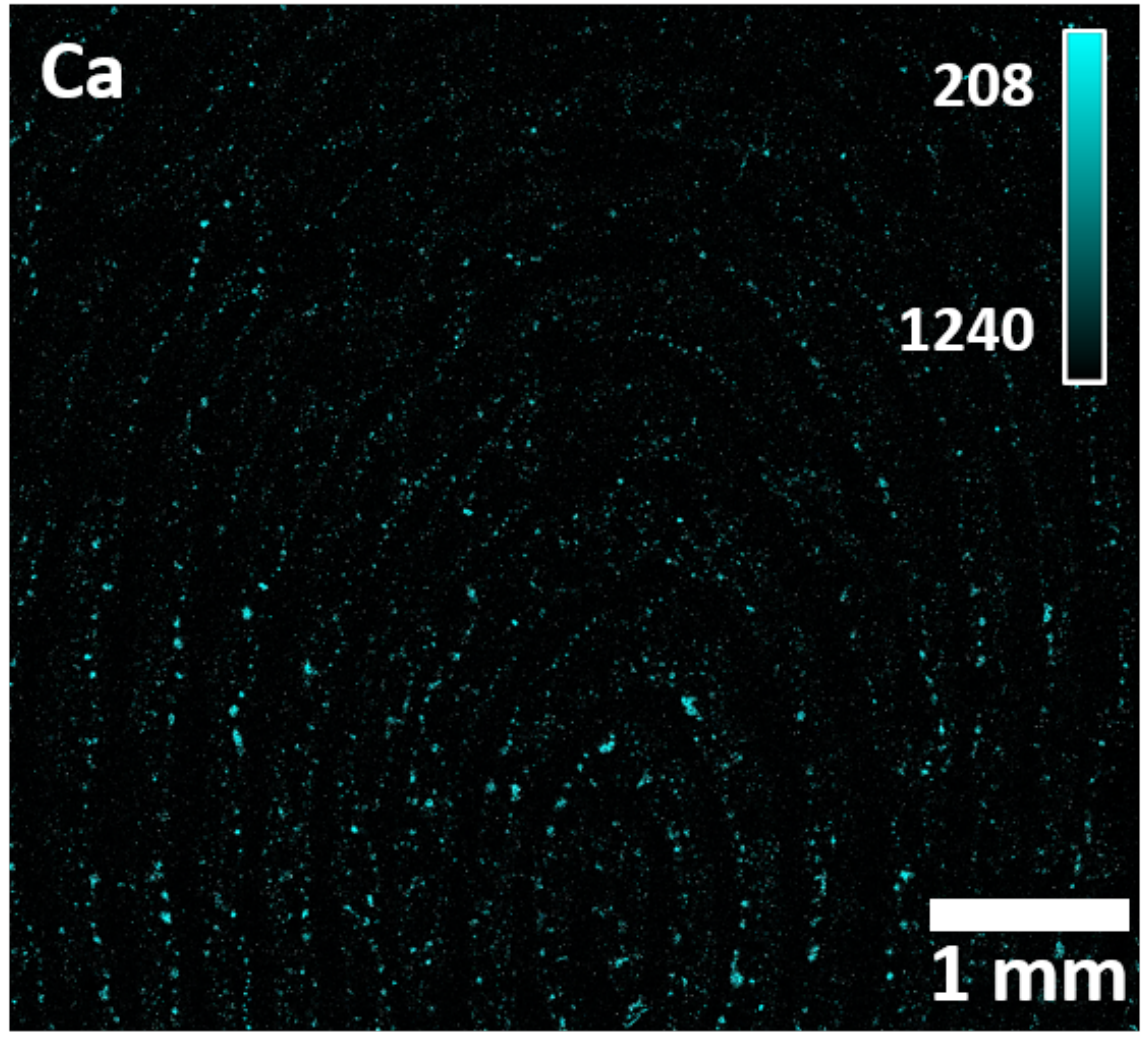

Supporting Figure 13 Large scale Ca map as shown in Figure 1 


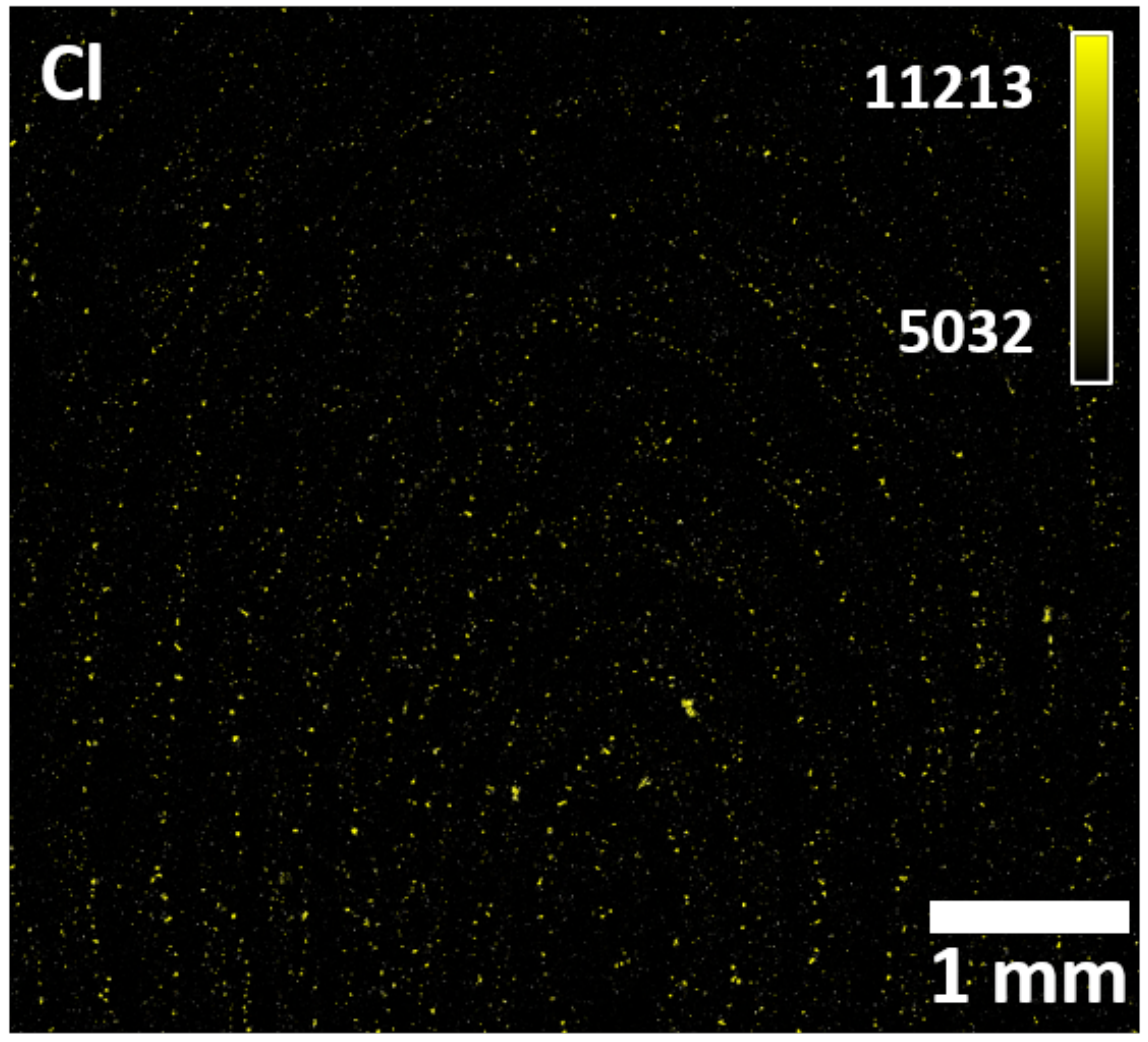

Supporting Figure 14 Large scale $\mathrm{Cl}$ map as shown in Figure 1

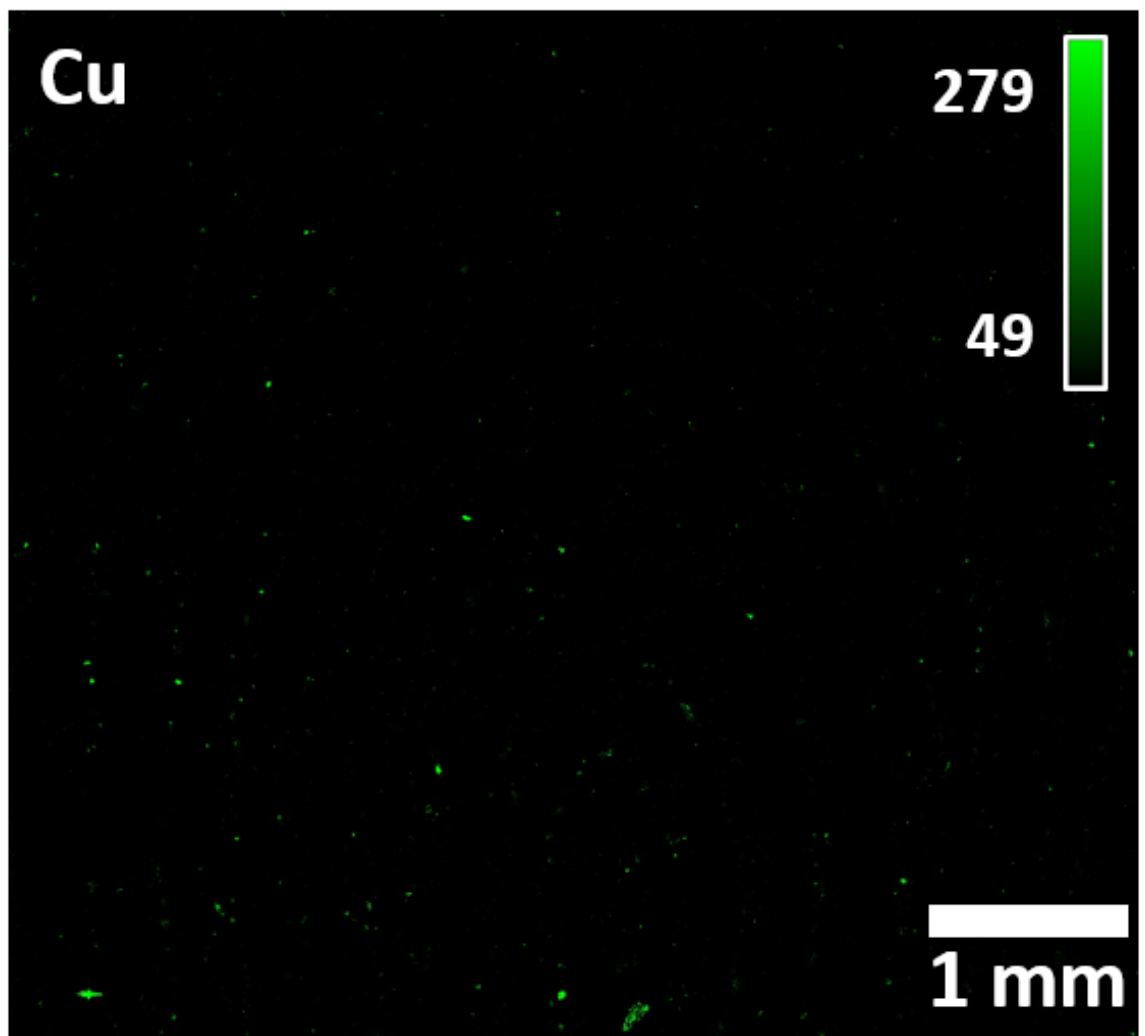

Supporting Figure 15 Large scale Cu map as shown in Figure 1 


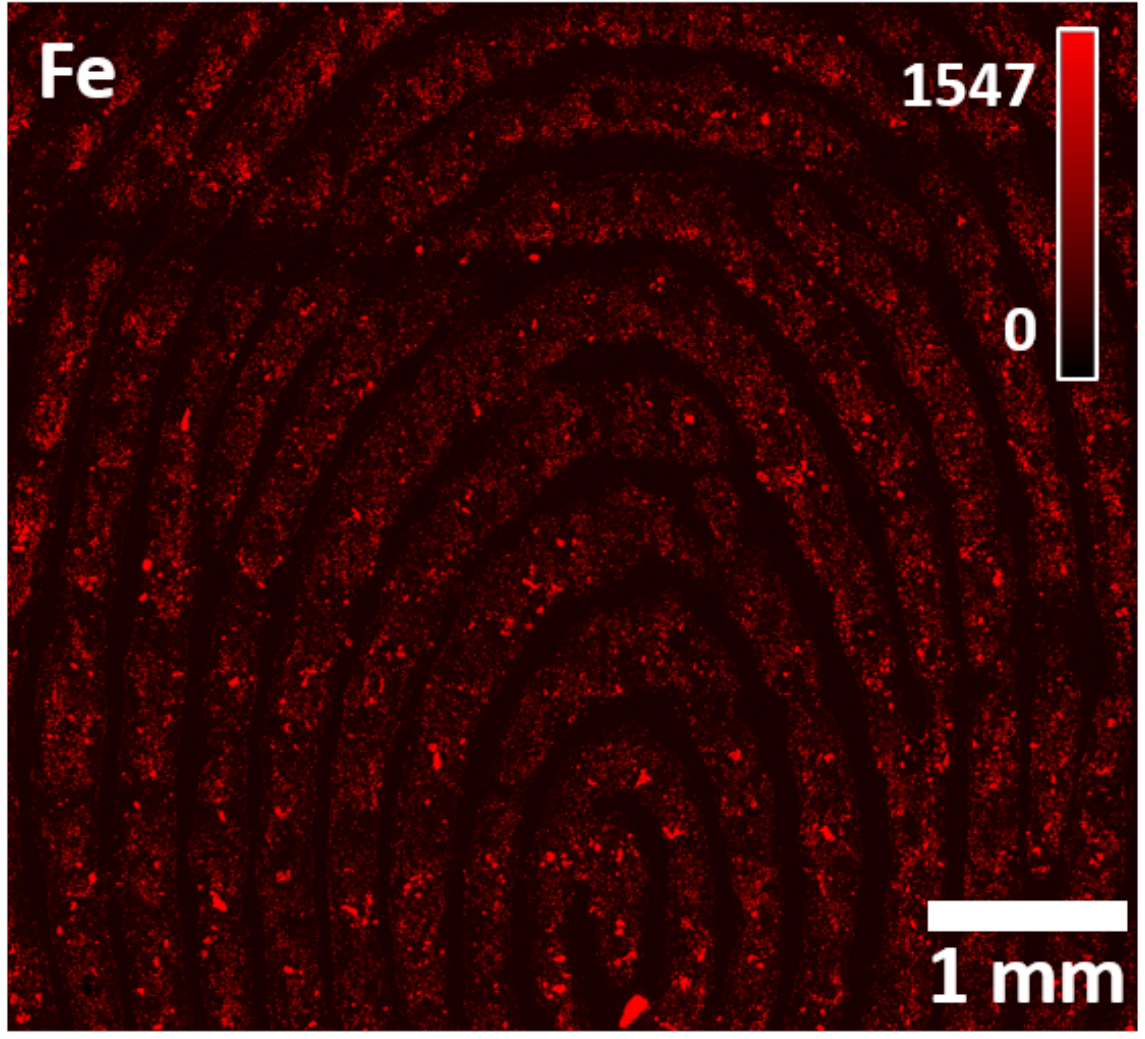

Supporting Figure 16 Large scale Fe map as shown in Figure 1

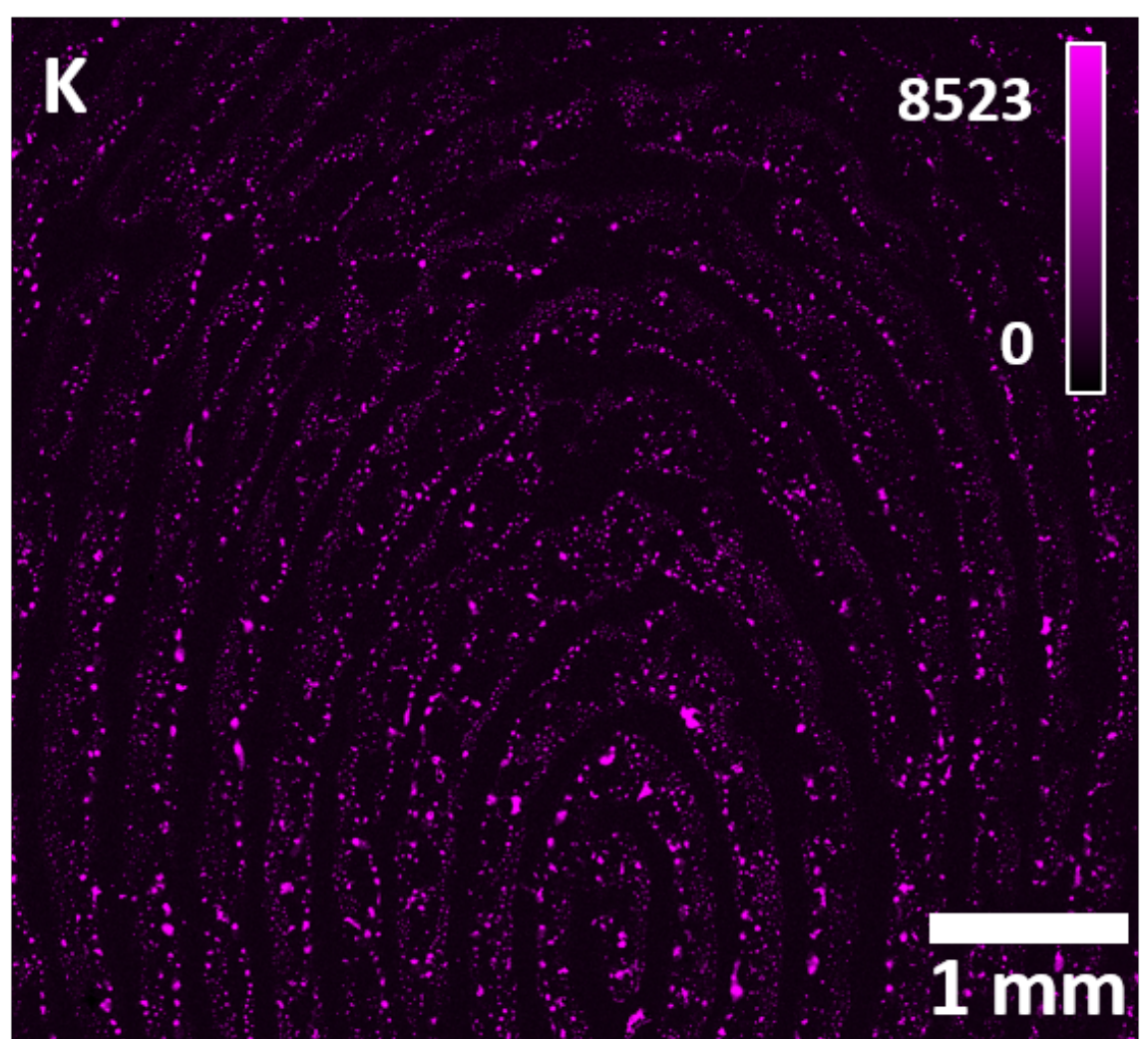

Supporting Figure 17 Large scale K map as shown in Figure 1 


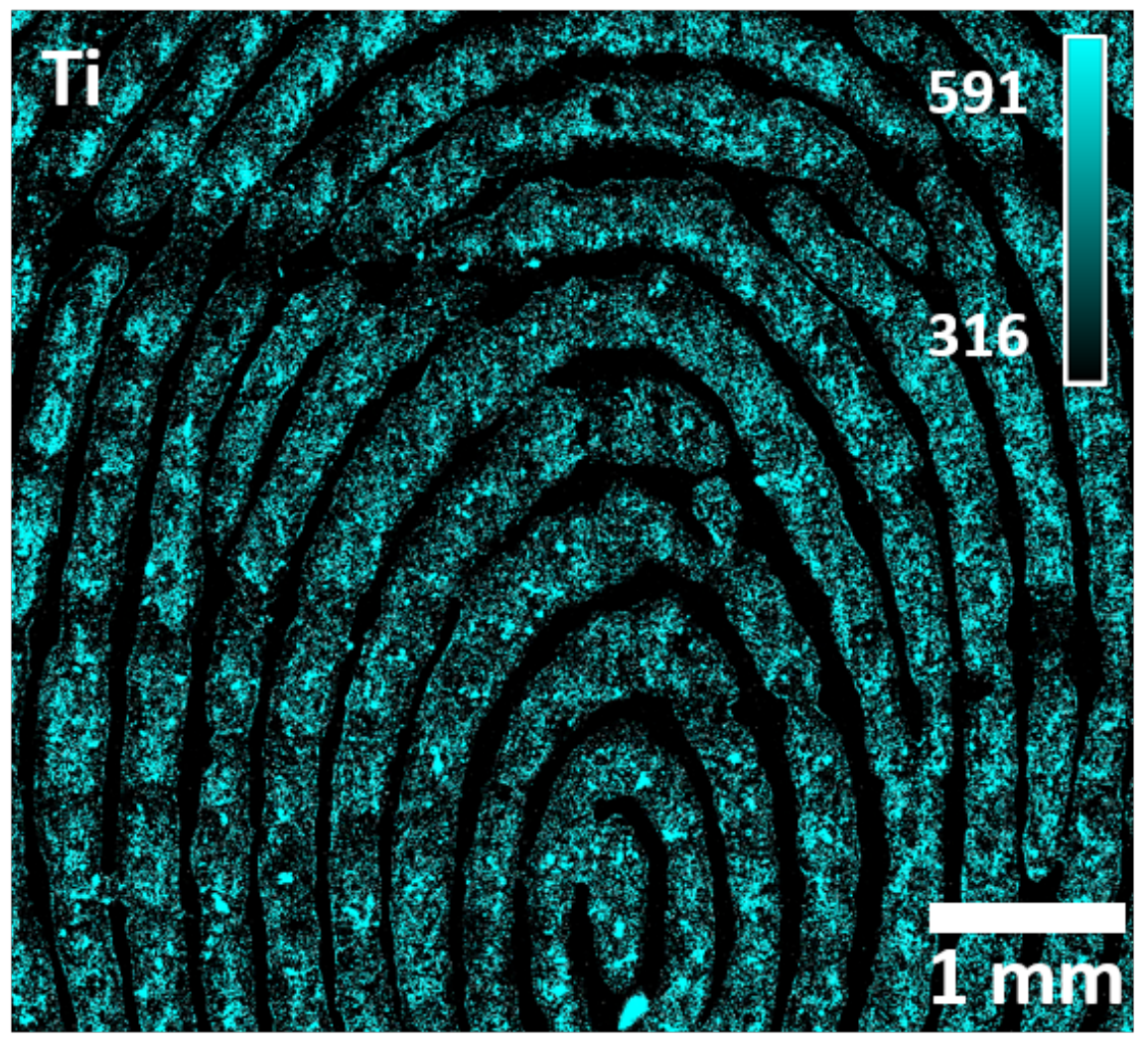

Supporting Figure 18 Large scale Ti map as shown in Figure 1

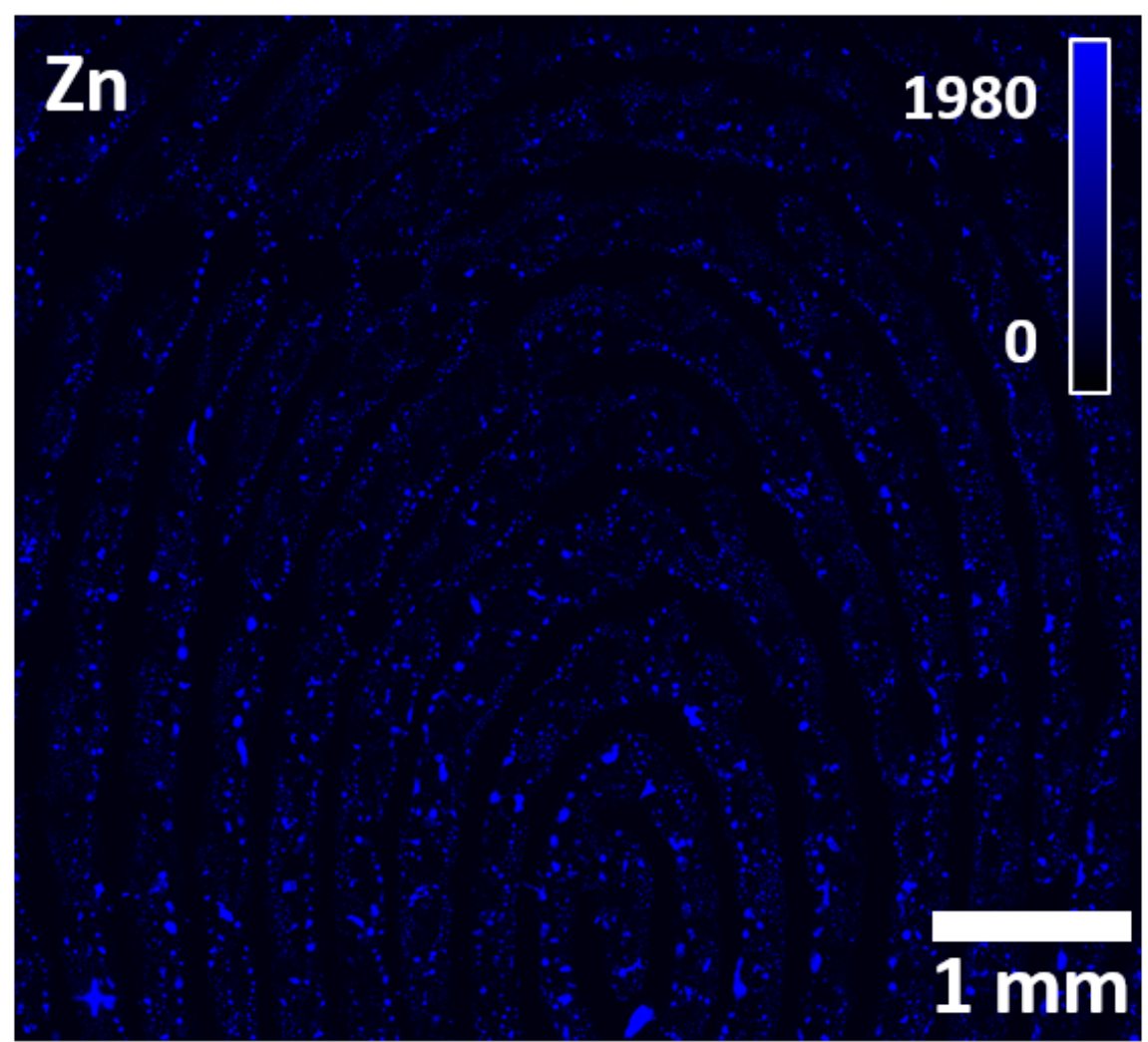

Supporting Figure 19 Large scale Zn map as shown in Figure 1 